\title{
Erratum to: Using Parameter Constraints to Choose State Structures in Cost-Effectiveness Modelling
}

\author{
Howard Thom $^{1}{ }^{1} \cdot$ Chris Jackson $^{2} \cdot$ Nicky Welton $^{1} \cdot$ Linda Sharples $^{3}$
}

Published online: 26 June 2017

(C) Springer International Publishing Switzerland 2017

\section{Erratum to: PharmacoEconomics \\ DOI 10.1007/s40273-017-0501-9}

The article Using Parameter Constraints to Choose State Structures in Cost-Effectiveness Modelling, written by Howard Thom, Chris Jackson, Nicky Welton, Linda Sharples, was originally published electronically on the publisher's internet portal (currently SpringerLink) on 24th March, 2017 with open access under the terms of the Creative Commons Attribution-NonCommercial 4.0 International License (http://creativecommons.org/licenses/bync/4.0/).

However, the license should have been the Creative Commons Attribution 4.0 International License (http:// creativecommons.org/licenses/by/4.0/), which permits use, duplication, adaptation, distribution and reproduction in any medium or format, as long as you give appropriate credit to the original author(s) and the source, provide a link to the Creative Commons license and indicate if changes were made. The original article has been updated.

The online version of the original article can be found under doi:10.1007/s40273-017-0501-9.

Howard Thom

Howard.thom@bristol.ac.uk

1 School of Social and Community Medicine, University of Bristol, Bristol, UK

2 Medical Research Council Biostatistics Unit, Cambridge, UK

3 Department of Medical Statistics, London School of Hygiene and Tropical Medicine, London, UK 